\title{
Duration-Dependant Effect of Exposure to Rubber Dust Particles on Lung Functional Status among Rubber Factory Workers
}

\author{
Gopathy Sridevi ${ }^{1}$, Chandrasekar $\mathrm{M}^{2}$ and Prema Sembulingam ${ }^{3}$ \\ 1. Department of Physiology, Sathyabama University Dental College and Hospital, Jeppiar nagar, Rajiv \\ Gandhi road (Old Mahabalipuram road), Chennai - 600 119. Contact No-9789968615 \\ 2. Department of Physiology, Meenakshi Medical College Hospital \& Research Institute \\ Enathur, Karrapettai Post, Kanchipuram - 631552. \\ ${ }^{3}$ Department of Physiology, Madha Medical college \& Research Institute, Kuntrathur main Road, Kovur, \\ Thandalam near Porur, Chennai- 600112
}

\begin{abstract}
Rubber dust particles affect the respiratory system by directly entering into the respiratory tract while breathing. We analysed the effect and the impact of duration of exposure to these dust particles on the lung volumes by pulmonary function test (PFT) in 4 groups of 60 male employees in a rubber factory. Group 1 Controls. .Group 2, 3 and 4 - test groups with 1-3years, 4-7 years and 8-11years exposure to rubber dust particles. Forced vital capacity $(F V C)$, forced expiratory volume in one second, (FEVI), FEV as a percentage of FVC (FEVI/FVC), forced expiratory flow 25-75\% (FEF 25-75\%), peak expiratory flow rate (PEFR) and maximum ventilatory volume (MVV) were assessed. The mean values of these variables (except for FVC) showed significant decline in Group 2, 3 and $4(p<0.000)$ compared to that of Group 1 and the decline was the maximum in Group 4 showing that lung function is affected by the rubber dust particles and the severity of the effect is duration-dependent, less in short time-exposure and more in long time-exposure. Knowing this fact may create awareness among the employers and the employees of rubber factories to plan for preventive measures.
\end{abstract}

KEY WORDS: Duration dependent, Lung volumes, Pulmonary function test, Rubber factory, Spirometry,

\section{INTRODUCTION}

Environmental pollution is a worldwide phenomenon posing a serious threat to the public health in the developed as well as developing countries. Among the major forms of pollution, air pollution seems to be the dangerous one because the particles and particulate matters from air combustion, industrial waste, liquid droplets etc, remain suspended in troposphere and float in the air making a direct attack on the vital systems of the body viz., cardiovascular system and respiratory system. Occupational hazards are equally dangerous because of the discharge of effluents and emissions from industries, solid waste disposal, automobile exhaust, degradation of soil, pesticide usage etc [1].

Rubber factories are one of the places where the employees face the occupational hazard. It is of greatest concern to the employees because they are directly exposed to the rubber particles and particulate matters suspended in the working environment. These particles are called PM10 and measures less than 10 microns in diameter and about $1 / 7^{\text {th }}$ the thickness of a human hair [2]. These are small enough to enter into the deepest parts of the lung and according to Ohya et al [3], such small particulate matters were more threatening because of their higher rubber transferase activity than the bigger particles measuring about $1.07 \mu \mathrm{m}$. These rubber particles can be dangerous not only through inhalation but also through direct contact with the skin. Direct contact with rubber was found to produce allergic dermatitis $[4,5,6,7,8,9,10]$. These particles were found to be dangerous not only to the human life but also to the plant life $[11,12]$ and aquatic species $[13,14$, 15]. Williams et al showed that air-borne rubber particles if inhaled, aggravated the latex sensitization, irritated the respiratory tract and induced asthma [16]. These rubber particles if entered into the body either through the skin or inhalation or ingestion, are capable of inducing mutagenicity and carcinogenicity [17]. The inhalation of the particles from the atmospheric air of work environment is by far the commonest route of entry of most of the hazardous substances. Lungs, by virtue of direct contact with the atmospheric air, are naturally the first to bear the onslaught of air contaminants. Though the literature evidences prove the rubber particle-hazards on various health problems, its direct impact on the lung functions and the duration-dependent effect of exposure to the rubber particles among the workers in a rubber factory is not explored enough. The present study travels through these new areas. 


\section{MATERIALSAND METHODS}

60 male subjects in the age group of 30 to 45 years were recruited for this study. Forty five of them were regular employees of a reputed rubber factory in Tamil Nadu. Another 15 were employees of the institute where the study was conducted. All were non-smokers and non-alcoholics with apparently normal health without any medical illness or on medication for some reason or the other. None of them were exposed to other known respiratory occupational hazards. They were divided into four groups with 15 subjects in each group. Group 1 was control group who were not exposed to the rubber dust particles. Other three groups were rubber factory employees with different durations of exposure to rubber dust particle environment for 8 hours per day with one day off per week. Group 2 - subjects with 1 to 3 years exposure. Group 3 - subjects with 4 to 7 years exposure. Group 4 - subjects with 8 to 11 years exposure to the rubber particles. Functional status of the lungs was assessed by conducting pulmonary function test (PFT). The subjects were instructed to report in the Physiology laboratory of Meenakshi Medical College in the forenoon. The purpose and procedure of the project was explained to the subjects and their consent for the study was obtained. The project was approved by the Institutional Ethical committee. PFT was recorded in computerized spirometer (MEDSPIROR) by single breath technique. The parameters studied were forced vital capacity (FVC), forced expiratory volume in 1st sec. (FEV1), FEVI/FVC ratio, forced expiratory flow 25-75\% (FEF 25-75\%), peak expiratory flow rate (PEFR) and maximum ventilatory volume (MVV). Prior to the recording, the subjects were given the explanation recording the spirometer and the spirogram and were trained well to blow into the mouth piece of the spirometer in a proper way. The data were analysed in SPSS, version 17.0 and the mean values with standard deviation (mean \pm SD) were obtained for all the variables. Significance between the groups and within the groups was obtained through ANOVA. Tukey's multiple comparison tests were performed to assess the significance between two groups. Significance level was fixed at $\mathrm{p}<0.05$.

\subsection{Anthropometric variables}

\section{RESULTS}

There was gradual increase in mean age of all the three groups compared to that of Group 1 (mean \pm SD: $32.12 \pm 4.45,35.33 \pm 5.04,38.67 \pm 4,27$ and $42.02 \pm 3.67$ ) (Table 1) and the difference between Groups 1 and 3, 1and 4 and 2 and 4 was highly significant ( $<0.001,0.000$ and 0.000 ); other anthropometrics viz., height, weight and BMI did not show any significant difference (Table 2).

\begin{tabular}{|c|c|c|c|c|}
\hline Variable & Group 1 & Group 2 & Group 3 & Group 4 \\
\hline Age $($ years $)$ & $32.13 \pm 4.45$ & $35.33 \pm 5.04$ & $38.67 \pm 4.27$ & $42.20 \pm 3.67$ \\
\hline Height $(\mathrm{cm})$ & $165.87 \pm 3.25$ & $166.73 \pm 3.31$ & $168.20 \pm 3.65$ & $169.27 \pm 4.61$ \\
\hline Weight $(\mathrm{kg})$ & $63.53 \pm 5.71$ & $67.93 \pm 7.27$ & $68.00 \pm 8.19$ & $67.20 \pm 7.67$ \\
\hline BMI $\left(\mathrm{kg} / \mathrm{m}^{2}\right)$ & $23.12 \pm 2.19$ & $24.23 \pm 2.51$ & $23.37 \pm 2.18$ & $23.26 \pm 2.58$ \\
\hline
\end{tabular}

Table 1. Anthropometric parameters

Values are expressed as Mean $\pm \mathrm{SD}$

Group 1 - Controls. Group $2-1$ to 3 years' exposure. Group 3 - 4 to 7 years' exposure Group $4-8$ to 11 years' exposure

\subsection{PFT Variables:}

FVC: The mean value of FVC in Group $2(114.33 \pm 16.34)$ was slightly more than that of Group 1 $(113.13 \pm 9.69)$. Group 3 and 4 showed slight decline $(109.20 \pm 13.72$ and $108.53 \pm 8.20)$ than Group 1 and 2 and the decline was maximum in Group 4 (Table 3). However, the differences were not statistically significant between the groups (Table 4)

FEV1: There was steady decline in the mean values of FEV1 from Group 1 till Group 4 and the decline was maximum in Group 4 (Table 3). The difference in the decline was highly significant between Groups 1 and $3(\mathrm{p}<0.000), 1$ and $4(\mathrm{p}<0.000)$ and 2 and $4(\mathrm{p}<0.003)($ Table 4$)$

FEV1/FVC ratio: The mean value of FEV1/FVC showed a steady decline in Group 2, 3 and 4 in comparison to that of Group 1. The value was maximum in Group 1 (116.20 \pm 5.85$)$ and minimum in Group 4 $(93.07 \pm 6.75)$ (Table 3). Between the groups, the difference was highly significant between Group 1 and $2(\mathrm{p}<$ $0.005), 1$ and 3 ( $p<0.000), 1$ and 4 ( $<<0.000), 2$ and $4(\mathrm{p}<0.000)$ and 3 and $4(\mathrm{p}<0.002)$. (Table 4$)$ 
FEF 25-75\%: The mean value of FEF25-75\% was maximum in Group 1 (94.93 \pm 8.93$)$ and minimum in Group $4(53.33 \pm 5.54)$ and the decline from Group 1 till group 4 was gradual (Table 3). The differences in the decline between the groups were highly significant $(\mathrm{p}<0.003$ and 0.000$)$ (Table 5).

Table 2. Anthropometric variables -Tukey's multiple comparisons between the groups

\begin{tabular}{|c|c|c|c|}
\hline Variable & $\begin{array}{l}\text { Difference } \\
\text { between }\end{array}$ & $\begin{array}{c}\text { Mean difference } \\
\pm \mathrm{SE}\end{array}$ & Sig \\
\hline \multirow{6}{*}{ Age } & G $1 \&$ G 2 & $-3.20 \pm 1.64$ & 0.197 \\
\hline & G $1 \&$ G 3 & $-6.53 \pm 1.64$ & $0.001 *$ \\
\hline & G $1 \&$ G 4 & $-10.07 \pm 1.64$ & $0.000 *$ \\
\hline & G $2 \&$ G 3 & $-3.33 \pm 1.64$ & 0.168 \\
\hline & G $2 \& G 4$ & $-6.87 \pm 1.64$ & $0.000 *$ \\
\hline & G $3 \&$ G 4 & $-3.53 \pm 1.64$ & 0.131 \\
\hline \multirow{6}{*}{ Height } & G $1 \& G 2$ & $-087 \pm 1.30$ & 0.910 \\
\hline & G $1 \&$ G 3 & $-2.33 \pm 1.30$ & 0.288 \\
\hline & G $1 \&$ G 4 & $-3.40 \pm 1.30$ & 0.055 \\
\hline & G $2 \&$ G 3 & $-1.47 \pm 1.30$ & 0.675 \\
\hline & $\mathrm{G} 2 \& \mathrm{G} 4$ & $-2.53 \pm 1.30$ & 0.221 \\
\hline & G $3 \&$ G 4 & $-1.07 \pm 1.30$ & 0.845 \\
\hline \multirow{6}{*}{ Weight } & G $1 \& G 2$ & $-4.40 \pm 2.65$ & 0.355 \\
\hline & G $1 \&$ G 3 & $-4.47 \pm 2.65$ & 0.342 \\
\hline & G $1 \&$ G 4 & $-3.67 \pm 2.65$ & 0.516 \\
\hline & G $2 \&$ G 3 & $-0.07 \pm 2.65$ & 1.000 \\
\hline & $\mathrm{G} 2 \& \mathrm{G} 4$ & $0.73 \pm 2.65$ & 0.993 \\
\hline & $\mathrm{G} 3 \& \mathrm{G} 4$ & $0.80 \pm 2.65$ & 0.990 \\
\hline \multirow{6}{*}{ BMI } & G $1 \&$ G 2 & $-1.11 \pm 0.86$ & 0.568 \\
\hline & G $1 \&$ G 3 & $-0.25 \pm 0.86$ & 0.991 \\
\hline & G $1 \& \mathrm{G} 4$ & $0.14 \pm 0.86$ & 0.998 \\
\hline & G $2 \&$ G 3 & $0.86 \pm 0.86$ & 0.749 \\
\hline & $\mathrm{G} 2 \& \mathrm{G} 4$ & $0.97 \pm 0.86$ & 0.670 \\
\hline & G $3 \&$ \& 4 & $0.11 \pm 0.86$ & 0.999 \\
\hline
\end{tabular}

Significance is indicted by *

PEFR: The mean value of PEFR was maximum in Group 1 and $2(102.40 \pm 2.21,102.40 \pm 3.22)$ and minimum in Group $4(91.87 \pm 6.61)$ and it declined gradually from Group 1 till Group 4. (Table 3). Statistical significance was observed in the decline between Group 1 and 3 (p<0.003), 1 and 4 (p < 0.000), 2 and 3 (p< 0.003 ) and 2 and 4 ( $<<0.000)$; however, the differences between Group 1 and 2 and 3 and 4 did not show any significance (Table 5).

MVV: A steady decline was observed in the mean of MVV from Group 1 with maximum value of $101.21 \pm 4.59$ till Group 4 with minimum of $73.47 \pm 3.81$ (Table 3). The differences between the groups were highly significant $(\mathrm{p}<0.000)$ except between the Groups 3 and $4(\mathrm{p}<0.858)$ (Table 5).

\section{DISCUSSION}

The prevalence of occupational health hazards and mortality has been reported to be unusually high among people of India. Different harmful contaminants in many industries act as pollutants to the environment. Millions of labourers on daily wages like stone grinding, paddy thrashing, weaving etc. face health hazards during occupational activities. However documentation on these is lacking. Similarly, evidences on the health hazards, especially lung functional status of rubber workers are also scanty. We assessed not only the effect of dust particles but also the impact of duration of exposure to the dust particles on the respiratory variables in the employees of a rubber factory by recording PFT through dynamic spirometry [18]. PFT is a simple, authentic, 
reliable and reproducible test to evaluate the functional status of the lungs and dynamic spirometry is part of PFT that studies the time-based lung volumes through forceful breathing. In normal breathing, many of the lung problems may not be exposed but forced breathing brings them out.

Table 3. Mean values of PFT variables

\begin{tabular}{|c|c|c|c|c|}
\hline Variable & Group 1 & Group 2 & Group 3 & Group 4 \\
\hline FVC (L) & $113.13 \pm 9.69$ & $114.33 \pm 16.34$ & $109.20 \pm 13.72$ & $108.53 \pm 8.20$ \\
\hline FEV1 (L) & $112.00 \pm 6.44$ & $106.33 \pm 5.51$ & $99.40 \pm 9.39$ & $95.80 \pm 9.60$ \\
\hline FEV1/FVC (L) & $116.20 \pm 5.85$ & $107.67 \pm 6.91$ & $102.20 \pm 7.21$ & $93.07 \pm 6.75$ \\
\hline FEF 25-75\% & $94.93 \pm 8.93$ & $85.53 \pm 6.64$ & $65.93 \pm 5.91$ & $53.33 \pm 5.54$ \\
\hline PEFR (L) & $102.40 \pm 2.21$ & $102.40 \pm 3.22$ & $96.13 \pm 5.32$ & $91.87 \pm 6.61$ \\
\hline MVV (L) & $101.21 \pm 4.59$ & $92.27 \pm 4.94$ & $72.47 \pm 4.45$ & $73.73 \pm 3.81$ \\
\hline
\end{tabular}

Values are expressed as Mean \pm SD

G - Group

Table 4. PFT variables - Multiple comparisons between the groups

\begin{tabular}{|c|c|c|c|}
\hline Variable & $\begin{array}{c}\text { Difference } \\
\text { between }\end{array}$ & $\begin{array}{c}\text { Mean difference } \pm \\
\text { SE }\end{array}$ & Sig \\
\hline \multirow{5}{*}{ FVC } & G 1 \& G 2 & $-1.20 \pm 4.53$ & 0.993 \\
\cline { 2 - 4 } & G 1 \& G 3 & $3.93 \pm 4.53$ & 0.821 \\
\cline { 2 - 4 } & G 1 \& G 4 & $4.60 \pm 4.53$ & 0.741 \\
\cline { 2 - 4 } & G 2 \& G 3 & $5.13 \pm 4.53$ & 0.671 \\
\cline { 2 - 4 } & G 2 \& G 4 & $5.80 \pm 4.53$ & 0.580 \\
\cline { 2 - 4 } & G 3 \& G 4 & $0.67 \pm 2.99$ & 0.999 \\
\hline \multirow{5}{*}{ FEV1 } & G 1 \& G 2 & $5.67 \pm 2.99$ & 0.218 \\
\cline { 2 - 4 } & G 1 \& G 3 & $12.60 \pm 2.99$ & $0.000^{*}$ \\
\cline { 2 - 4 } & G 1 \& G 4 & $16.20 \pm 2.99$ & $0.000^{*}$ \\
\cline { 2 - 4 } & G 2 \& G 3 & $6.93 \pm 2.99$ & 0.090 \\
\cline { 2 - 4 } & G 2 \& G 4 & $10.53 \pm 2.99$ & $0.003^{*}$ \\
\cline { 2 - 4 } & G 3 \& G 4 & $3.60 \pm 2.99$ & 0.603 \\
\hline \multirow{5}{*}{ FEV1/FVC } & G 1 \& G 2 & $8.53 \pm 2.45$ & $0.005^{*}$ \\
\cline { 2 - 4 } & G 1 \& G 3 & $14.00 \pm 2.45$ & $0.000^{*}$ \\
\cline { 2 - 4 } & G 1 \& G 4 & $23.13 \pm 2.45$ & $0.000^{*}$ \\
\cline { 2 - 4 } & G 2 \& G 3 & $5.47 \pm 2.45$ & 0.126 \\
\cline { 2 - 4 } & G 2 \& G 4 & $14.60 \pm 2.45$ & $0.000^{*}$ \\
\cline { 2 - 4 } & G 3 \& G 4 & $9.13 \pm 2.45$ & $0.002^{*}$ \\
\hline
\end{tabular}

Depending upon the lung functional status, the results of the dynamic PFT categorizes the subjects into 3 groups: people with a. normal lung function, b. obstructive disease and c. restrictive disease [19, 20, 18].

In obstructive diseases like asthma, bronchitis, emphysema etc, respiratory passage is obstructed and the airway resistance is increased; this makes the forceful breathing difficult without affecting the normal breathing. It is well expressed by lowering the FEV1 and FEF $25-75 \%$.

On the other hand, in restrictive diseases, like fibrosis, pneumonia, pulmonary edema, neuromuscular disorders affecting the respiratory muscles etc, the stiffness of the lung tissues increases and the expansibility (compliance) of the lungs is reduced resulting in more decrease in FVC and FEV1/FVC ratio and a slight decrease in FEV1 and FEF 25-75\%. MVV depends more upon the effort of the person in forcing the air out by contracting the respiratory muscles. So it may be reduced in both obstructive and restrictive conditions. However, the reduction is more in restrictive diseases than in obstructive diseases [19, 20, 18]. PEFR in turn, 
depends upon the rate at which the maximal alveolar pressure is attained and the initial stretch of the lungs before starting the blow of the air with the help of the basal strength and force of contraction of the respiratory muscles.

Table 5.PFT variables - Multiple comparisons between the groups

\begin{tabular}{|c|c|c|c|}
\hline Variable & $\begin{array}{l}\text { Difference } \\
\text { between }\end{array}$ & $\begin{array}{c}\text { Mean difference } \pm \\
\text { SE }\end{array}$ & Sig \\
\hline \multirow{6}{*}{ FEF $25-75 \%$} & G $1 \&$ G 2 & $9.20 \pm 2.51$ & $0.003 *$ \\
\hline & G $1 \&$ G 3 & $28.80 \pm 2.51$ & $0.000 *$ \\
\hline & G $1 \&$ G 4 & $42.40 \pm 2.51$ & $0.000 *$ \\
\hline & G $2 \&$ G 3 & $19.60 \pm 2.51$ & $0.000 *$ \\
\hline & G $2 \& G 4$ & $33.20 \pm 2.51$ & $0.000 *$ \\
\hline & G $3 \&$ G 4 & $13.60 \pm 2.51$ & $0.000 *$ \\
\hline \multirow{6}{*}{ PEFR } & $\mathrm{G} 1 \& \mathrm{G} 2$ & $0.00 \pm 1.72$ & 1.000 \\
\hline & G $1 \&$ G 3 & $6.27 \pm 1.72$ & $0.003^{*}$ \\
\hline & G $1 \&$ G 4 & $10.53 \pm 1.72$ & $0.000^{*}$ \\
\hline & G $2 \&$ G 3 & $6.27 \pm 1.72$ & $0.003 *$ \\
\hline & G $2 \& \mathrm{G} 4$ & $10.53 \pm 1.72$ & $0.000 *$ \\
\hline & G $3 \& \mathrm{G} 4$ & $4.27 \pm 1.72$ & 0.070 \\
\hline \multirow{6}{*}{ MVV } & $\mathrm{G} 1 \& \mathrm{G} 2$ & $9.00 \pm 1.61$ & $0.000^{*}$ \\
\hline & G $1 \&$ G 3 & $28.80 \pm 1.61$ & $0.000^{*}$ \\
\hline & $\mathrm{G} 1 \& \mathrm{G} 4$ & $27.53 \pm 1.61$ & $0.000^{*}$ \\
\hline & G $2 \&$ G 3 & $19.80 \pm 1.61$ & $0.000 *$ \\
\hline & G $2 \&$ G 4 & $18.53 \pm 1.61$ & $0.000^{*}$ \\
\hline & G $3 \&$ G 4 & $-1.21 \pm 1.61$ & 0.858 \\
\hline
\end{tabular}

If one or the other of these factors is affected as in case of obstructive and/or restrictive respiratory disorders, PEFR will be reduced [21]. Based on these facts, the results of the present study throws brighter light on the adverse effects of rubber dust particles on the lung functional status and the positive correlation between the duration of exposure to rubber dust particles and the lung volumes. FEV1, FEV1/FVC, FEF 25-75\%, PEFR and MVV showed steady decline from 1 to 3 years' exposure till 7 to 11 years' exposure making it clear that the adverse effect is less in short term-exposures and more in long-term exposures. As decrease in these volumes are attributed to obstructive and restrictive lung disorder, it is possible that the test group subjects of our study are already affected with or may be heading towards these lung disorders. Decline in lung function was reported already in occupational exposure to combustion particulates in boiler makers, construction workers and gas and oil fired plant workers [22]. Gold et al observed respiratory symptoms and a reduction of peak expiratory flow in school children exposed to particulate matter of size PM2.5 and PM 10 and ozone (O3) [23].

The possible mechanism for this is that, inhalation of these dust particles may get deposited on the alveolar lining which decreases the ventilation-perfusion ratio and may restrict the expiratory capacity and normal expansion of the lungs. This deposition may also lower the total lung capacity (TLC) in them. The present findings are well in line with the findings of Gupta et al who reported a significant positive correlation between the decrement in values of FEV1/FVC and a rise in the ratio of residual volume (RV)/TLC in rubber factory workers in India who inhale increased concentrations of particulate load [24]. Another study by Okwari et al reported that a chronic exposure to wood dust impairs lung function with a decline in FVC, FEV1, FEV1\% and PEFR in timber workers [25]. Yet another study implied that exposure to particulate matter in wood dust could lead to a variety of lung problems, including chronic airflow obstruction with a decrease in FEF, PEF and respiratory symptoms like cough, phlegm, breathlessness, wheezing, and nasal symptoms [26]. Sripaiboonkij et al reported that exposure to wood dust from the rubber tree increased the risk of nasal symptoms, wheeze, asthma and skin symptoms and reduced spirometric lung volumes [27]. According to the family doctor.org editorial staff, respiratory system is the most affected one with diseases like bronchitis, asthma, emphysema etc in a factory environments because polluted air with lot of harmful dust particles, fumes, smoke, gases, vapours, mists etc enter directly into the respiratory tract while breathing and the decline in lung function and duration of exposure to rubber particles are directly proportional, more the period of exposure more the decline in lung functions [28]. The results of the present study confirm this claim. 


\section{SCOPE OF FURTHERSTUDY:}

As rubber processing is a complicated work involving many procedures like compounding, extrusion, molding, vulcanization etc, lot of chemical substances are released into the environment [29]. It is necessary to go into the details of the agents responsible for causing decline in lung functions which may help to provide protection to the employees.

\section{PRECAUTIONS:}

- Employees may be provided with the copies of the material safety data sheets (MSDSs) that carry the information regarding the products to which the employee is exposed so that the employee can carry it with him when he sees the doctor for his ailment.

- The working place should be well ventilated which may remove or reduce the pollutants and toxins from the working environment.

- Employees may be instructed to use a respirator, a device that can be worn over the mouth and nose; this helps to filter and clean the air before it enters into body.

- Employees should be educated regarding the proper fitting and use of the device and cleaning it after every use.

\section{CONCLUSION}

It is concluded from the present study that exposure to rubber dust particles decreases the lung functions and explains the respiratory complications faced by employees exposed to occupational dust. Studies of this sort may help the industries to set up a safe background and adopt necessary methods to reduce the suspended dust particles in the working atmosphere to protect the employees from this type of occupational health hazards.

\section{REFERENCES}

[1] "Pollution - Definition from the Merriam-Webster Online Dictionary". Merriam-webster.com. http://www.merriamwebster.com/dictionary/pollution.

[2] Levy D, Sheppard L, Checkoway H, Kaufman J, Lumley T, Koenig J, Siscovick D, Levy D. 2001 . A case-crossover analysis of particulate matter air pollution and out of hospital primary cardiac arrest, Epidemiology (Cambridge, Mass) 2(12): 193-9.

[3] Ohya, N.; Tanaka, Y.; Wititsuwannakul; Koyama, T.Activity of rubber transferase and rubber particle size in Hevea latex.Journal of Rubber Research 2000 Vol. 3 (4): 214-221

[4] Sullivan, J.B., Jr., M. Van Ert, and R. Lewis. 1992. Chemical hazards in the tire and rubber manufacturing industry. In J.B. Sullivan, Jr. and B.R. Krieger (eds.). Hazardous materials toxicology, clinical principals of environmental health. Williams and Wilkins, Baltimore, MD. Pp. 516-532.

[5] Varigos, G.A. and D.R. Dunt. 1981. Occupational dermatitis. An epidemiological study in the rubber and cement industries. Contact Dermatitis 7: 105-110.

[6] Jordon, W.P., Jr. 1971. Contact dermatitis from $N$ - isopropyl- $N$-Phenylparaphenylenediamine. Archives of Dermatology 103:85-.

[7] Alfonso, C. 1979. Allergic contact dermatitis to isopropylaminodiphenylamine (IPPD). Contact Dermatitis 5: 145-147.

[8] Ancona, A., F. Monroy, J. Fernández-Diez. 1982. Occupational dermatitis from IPPD in tyres. Contact Dermatitis 8: 91 -94.

[9] Kilpikari, I. 1982. Occupational contact dermatitis among rubber workers. Contact Dermatitis 8: 359-362.

[10] Zina, A.M., P.G. Bedello, D. Cane, S. Bundino, and A. Benedetto. 1987. Dermatitis in a rubber tyre factory. Contact Dermatitis 17: $17-20$

[11] Smith, C.W., S.H. Wender, and C.A. Nau. 1969. Growth and free proline content of tobacco callus and HeLa cells exposed in vitro to rubber dust and carbon black. American Industrial Hygiene Association Journal 30: 402-406.

[12] Mehta, S.K. and J.P. Gaur. 1999. Heavy-metal- induced proline accumulation and its role in ameliorating metal toxicity in Chlorella vulgaris. New Phytologist 143: 253-259

[13] Goudey, J.S. and B.A. Barton. 1992. The toxicity of scrap tire materials to selected aquatic organisms. A report prepared for the Souris Basis Development Authority, Regina Saskatchewan. 43 pp. 32

[14] Nelson, S.M., G. Mueller, and D.C. Hemphill. 1994. Identification of tire leachate toxicants and a risk assessment of water uality effects using tire reefs in canals. Bulletin of Environmental Contamination and Toxicology 52: 574-581.

[15] Gualtieri, M., M. Andrioletti, P. Mantecca, C. Vismara, and M. Camatini. 2005. Impact of tire debris on in vitro and in vivo systems. Particle and Fibre Toxicology 2: 1 available at http://www.particleandfibretoxicology.com/content/2/1/1.

[16] Williams, P.B., A. Akasawa, S. Dreskin, and J.C. Selner. 1996. Respirable tire Fragments contain specific IgE-binding and bridging latex antigens. Chest 109: 13S. 38

[17] Brandäo, F.M. 1990. Rubber.In R.M. Adams (ed.). Occupational skin disease, 2nd edition. W.B. Saunders Company, Philadelphia.462-485

[18] Timmothy J Barreiro and Irene Perrillo. 2004. An approach to interpreting spirometry. American Family Physician, Volume 69, $1107-1114$

[19] Ruppel GL, 2012. Pulmonary function testing.Respir Care. 2012 Jan;57(1):165-75. http://www.ncbi.nlm.nih.gov/pubmed/22222123.

[20] http://www.morgansci.com/pulmonary-function-solutions/what-is-a-test-pulmonary-function-test/)

[21] K.Sembulingam, PremaSembulingam, V. Poornodai, Gigi Chandran. 2013. Effect of oil pulling on peak flow rate. International Journal of Research in Health Sciences. Volume 1, Issue 3. 134-138

[22] Hauser R, Eisen EA, Pothier L, Christiani DC. 2001.A prospective study of lung function among boilermaker construction workers exposed to combustion particulates, American Journal of Industrial Medicine 5(39): 454-62

[23] Gold DR, Damokosh AI, Arden Pope C, Dockery DW, McDonnell WF, Serrano P, Retama A, Castillejos M. 1999.Particulate and Ozone Pollutant Effects on the Respiratory Function of Children in Southwest Mexico City, Epidemiology (Cambridge, Mass) 1(10): 8-16. 
[24] Gupta P, Makhijani SD, Meenakshi C. 1988. Pulmonary function tests on rubber factory workers exposed to polynucelar aromatic hydrocarbons, Indian Journal of Physiology 52(2): 71-5.

[25] Okwari OO, Antai AB, Owu DU, Peters EJ, Osim EE.2005.Lung function status of workers exposed to wood dust in timber markets in Calabar, Nigeria ,African Journal Medical Sciences34(2):141-5.

[26] ShamssainMH.Thorax 1992, Pulmonary function and symptoms in workers exposed to wood dust, Occupational Environmental Medicine 66(7):442-7.

[27] Sripaiboonkij P, Phanprasit W, Jaakkola MS. 2009. Respiratory and skin effects of exposure to wood dust from the rubber tree Heveabrasiliensis, Occupational Environmental Medicine 66(7) : 442-7

[28] Family doctor.org editorial staff. http://familydoctor.org/familydoctor/en/prevention-wellness/staying-healthy/occupationalhealth/occupational-respiratory-disease.htmlBrowsed on 18.11.2013

[29] Joseph P. Sullivan. http://www.ardeacon.com/pdf/Assessment_Environmental_Toxicity_Report.pdf Browsed on 18.11.2013 